\title{
The queering of medicine
}

I was I4 when my parents split up. It got so crazy that my brother and I needed our own lawyer. I suddenly had to become an adult in order to make sense out of chaos. As part of that process, I told my Dad that I was gay. He kicked me out and told me that if I ever came back he'd kill me. I was barely I7. I dropped out of school, got a job, and did what I needed to do to survive. Now I'm I9, finished school, and building a new life in a different city. I know where my 2 feet are and how to stand on them; hate made more resilient. But the thing that haunts me is the realization that some people, like my Dad, dismiss me purely because I love other men. - Jeff Mavraganis

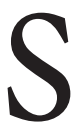
tatistics Canada recently released an important study ${ }^{1}$ designed to assess if sexual identity had any connection to accessing a family physician, working with other health care providers, taking advantage of health promotion and disease prevention strategies, and having unmet health needs.

The study confirmed that lesbigay people use our health care system differently. Lesbian women are less likely to access regular pap tests, have mammograms and see a family physician when compared with heterosexual women. Lesbigay people are more likely to access mental health services than heterosexuals, and bisexual people are 2 to 3 times more likely to perceive their mental health as fair to poor. Disturbingly, all sexual minorities had unmet health care needs at rates much higher than heterosexuals. The struggle for equality, even in Canada, is far from over.

The Gay and Lesbian Medical Association also emphasizes the unique nature of this population. It reports that gay men are particularly vulnerable to body image and eating disorders, and sexually transmitted diseases, and have increased rates of death from prostrate, testicular, and colon cancer. Lesbian women are particularly vulnerable to breast cancer, poor heart health, gynecological cancers and osteoporosis. Transgendered persons underutilize health care services,

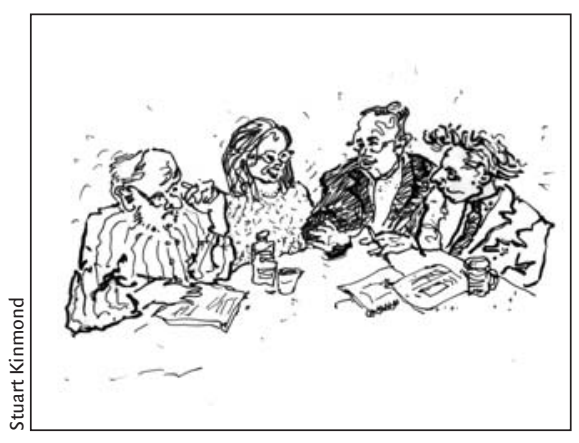

are vulnerable to complications arising from supervised and unsupervised hormone use and are less likely to share their full health history with care providers. In general, lesbigay and transgendered people are described as having higher rates of mental health concerns, tobacco use and substance dependence and abuse. ${ }^{2}$ These are critical issues that we must address with culturally sensitive professionalism. Which brings me to our profession.

I was washing up in the emergency department when I heard my supervisor crack a gay joke to the charge nurse. They both chuckled, enjoying a moment of humour in an otherwise stressful environment. They didn't know it but they were laughing at people like me. Sadly, I wanted to do my residency there, but he was the program director. I knew that my energy and innovation had to find a better home elsewhere. — Derek Puddester

Studies have revealed that over $40 \%$ of medical trainees and practising physicians have witnessed homophobic remarks in the workplace. ${ }^{3}$ An American study of lesbigay physicians indicated that only ${ }_{2} \%$ of them felt treated as equals within the profession. ${ }^{4}$ I suspect if we repeated these studies today the numbers would be more positive. But we're kidding ourselves if we believe that the house of medicine is free of homophobia and heterosexism.

Every one of us practising medicine in Canada has work to do. We ought to be reflecting on our own assumptions and beliefs about lesbigay and trans- gendered people, evaluating the lesbigay- and transgendered-friendliness of our working and learning environments, informing ourselves of the unique health care needs of sexual minorities and their families, and training our students, residents, and colleagues to levels of excellence in lesbigay and transgendered cultural competence and sensitivity.

As physicians, we are committed to promoting health for all, including heterosexual, bisexual, homosexual, transgendered, questioning and 2-spirited people. At their core, these words are all different names for the same thing: the love one person feels for another. We need to honour love in our work, regardless of whom it is between. After all, if we demonstrate heterosexism or homophobia, we become a health hazard.

\section{Derek Puddester MD \\ Director, Faculty Wellness Program University of Ottawa \\ Ottawa, Ont.}

Dr. Puddester thanks Jeff Mavraganis for his suggestions and guidance in the crafting and preparation of this manuscript.

\section{REFERENCES}

I. Tjepkema M. Health care use among gay, lesbian, and bisexual Canadians. Available: www.statcan.ca /english/freepub/82-003-XIE/2008001/article/I0532 -en.htm (accessed 2008 Apr I3).

2. Top GLMA. Ten issues to discuss with your healthcare provider. Available: www.glma.org/ index.cfm? fuseaction=Page.viewPage $\&$ page $I D=58$ 6 (accessed 2008 Apr I3).

3. Cook DJ, Griffith LE, Cohen M, et al. Discrimination and abuse experienced by general internists in Canada. J Gen Intern Med 1995; I0:565-72.

4. Schatz B, O'Hanlan KA. Anti-gay discrimination in medicine: results of a national survey of lesbian, gay and bisexual physicians. San Francisco (CA): Gay and Lesbian Medical Association; 1994.

Have you got an opinion about this article? Post your views at www.cmaj.ca. Potential Salon contributors are welcome to send a query to salon@cma.ca. 